\title{
Influence of Contact Lens Materials and Cleaning Procedures on Bacterial Adhesion and Biofilm Formation
}

\author{
Auemphon Mordmuang (D) \\ Lunla Udomwech (iD) ${ }^{1,2}$ \\ Kulwadee Karnjana (iD \\ 'School of Medicine, Walailak University, \\ Nakhon Si Thammarat, Thailand; \\ ${ }^{2}$ Walailak University Hospital, Walailak \\ University, Nakhon Si Thammarat, \\ Thailand
}

\begin{abstract}
Purpose: The present study aimed to compare the existing soft contact lens (CL) materials regarding their influence on bacterial biofilm formation and adhesion susceptibility. Then, the study was designed to investigate the effectiveness of various disinfecting solutions and evaluate the ability of cleaning regimens in terms of anti-bacterial adhesion and biofilm removal on different soft CL materials.
\end{abstract}

Methods: Bacterial biofilm formation on CLs was evaluated by biomass assay. Adhesion assay and standard plate count were carried out at time-interval periods within $24 \mathrm{~h}$. Various $\mathrm{CL}$ disinfecting procedures were assessed for their efficacy to remove biofilm and reduce bacterial adhesion. Scanning electron microscopy (SEM) was performed for the morphological assessment of bacterial biofilm.

Results: Printed hydroxyethyl methacrylate (HEMA) CLs significantly demonstrated more biofilm staining and bacterial attachment when compared with non-printed HEMA CLs, while the Filcon II 3 and Nesofilcon A CLs possessed less biofilm biomass and adherent cells. Staphylococcus aureus and Pseudomonas aeruginosa represented the highest biofilm producing bacteria on HEMA-based materials in this study. The disinfecting regimen with the highest efficacy was the two-step system, first using multipurpose disinfecting solution containing edetate disodium and sorbic acid (MPDS+EDSA), followed by soaking in multipurpose solution (MPS). The regimen demonstrated the greatest effect against the pre-formed biofilm and the adhesion activity of $S$. aureus and $P$. aeruginosa on the soft CLs. The SEM micrographs confirmed the morphological changes of bacterial biofilm after disinfecting and revealed that the two-step system treated CLs displayed less adherent bacteria.

Conclusion: HEMA-based soft CLs may facilitate bacterial biofilm formation and adhesion capability. The two-step system was the most effective regimen for biofilm removal, where the soaking period in the disinfecting solution of the no-rub regimen should last more than 6 $\mathrm{h}$ to remove pre-formed biofilm.

Keywords: lens materials, bacterial adhesion, biofilm formation, disinfection, soft contact lens

\section{Introduction}

It is estimated that over 153 million people worldwide $(2.67 \%$ of the world's population) are visually impaired from uncorrected refractive errors. ${ }^{1}$ Although the most common method for correcting the refractive error is the use of spectacles, it was reported that $16.7 \%$ of adult Americans (40.9 million) wear CLs. ${ }^{2}$ The prevalence of CL use observed in some population-based studies can be even
Correspondence: Kulwadee Karnjana School of Medicine, Walailak University, Nakhon Si Thammarat, Thailand

Tel +66 7567-280 l

Fax +6675 672-807

Email kulwadee.kr@wu.ac.th 
greater in number; for example, a study among medical students from Saudi Arabia indicated $40.5 \%$ of the students wore CLs. ${ }^{3}$ CLs have a greater advantage over glasses in many aspects, such as cosmetics, compatibility for anisometropia, shorter adjustment period, resolving weight issues in high refractive error, and treatment of choice for irregular astigmatism. They are widely available, especially soft CLs, which can be bought readily from pharmacies, optical stores, and even convenience stores in some countries. ${ }^{4}$ However, the popularity of CLs also brought more CL-related complications, which are most frequently caused by inappropriate $\mathrm{CL}$ care routines. $^{5-8}$ A high proportion of $\mathrm{CL}$ users committed some mistakes in their CL care practice. ${ }^{9,10}$ Nevertheless, adherence to an improper care habits is a risk factor for developing CL-related microbial keratitis, which can lead to permanent visual loss. ${ }^{11,12}$ Then, several systems of CL cleaning and disinfection were developed to prevent these complications.

Wearing CLs creates a barrier for corneal respiration, which restricts direct exposure to the atmosphere and reduces corneal oxygenation. A prolonged period of CL wear in conjunction with the less oxygen permeability, especially for CLs made of older generation materials such as hydroxyethyl methacrylate (HEMA), can result in corneal hypoxia. This can cause discomfort, dryness, corneal edema, and increased risks of serious ocular infection. ${ }^{11}$ Newer generation CL materials, such as silicone hydrogel and hypergel (a novel hydrogel with higher water content), were developed not only for the comfort of users but also to allow for more oxygen permeability. Their unique characteristics of different materials may interact with and influence different organisms. In this study, representative soft CLs available in Thailand were selected to represent by different materials: HEMA, HEMA-based, silicone hydrogel, and hypergel for investigation.

Apart from human-related factors involved in caring for CLs, the properties of the CL itself are another inevitable factor. Water content, hydrophobicity, and roughness are examples of how different materials can interact differently with microorganisms. ${ }^{12-14}$ The most common group of microorganisms that cause CL-related eye infection is bacteria, such as Pseudomonas spp, Staphylococcus spp., Streptococcus spp., Hemophilus spp., Klebsiella spp., and Serratia spp. ${ }^{14-16}$ The main important virulent factor of the bacteria is their ability to form biofilms and produce adhesion factors. $^{17,18}$ Bacterial biofilms facilitate prolonged contamination of CLs and the persistence of organisms in the CL storage case. ${ }^{19}$ Moreover, bacterial adhesion has been studied in terms of the chemical and physical properties of both bacterial cells and CL surface. Hydrophobicity of CL favors certain strains of bacteria by material-dependent manners. CLs with hydrophilic surface are more prone to hydrophilic bacterial adhesion, whereas hydrophobic CL surface accommodates more hydrophobic bacteria. ${ }^{20,21}$ Surface roughness of CLs has been proposed to play a role in adherent susceptibility; however, disputing data in this issue leaves the question inconclusive. ${ }^{22}$ Therefore, the aims of this study were, firstly, to determine the bacterial biofilm formation and adhesion susceptibility on different materials of CL surface and secondly, to study the effectiveness of different CL cleaning and disinfecting procedures using different products since they interact with materials in different ways. ${ }^{23-25}$ Five strains of pathogenic bacteria causing eye infection including Staphylococcus epidermidis, S. aureus, Escherichia coli, Klebsiella pneumoniae, and Pseudomonas aeruginosa were selected for this experiment. The capability of biofilm production and adhesion activity of the bacteria were assessed by direct measure the biofilm biomass and number of adherent cell, respectively. Furthermore, the ultramicroscopic characteristics of bacteria-surface interactions were observed using scanning electron microscope.

\section{Materials and Methods \\ Contact Lens Materials and Properties}

Five soft CL brands of different materials were selected to study (Table 1) and the commercial details of each manufacturer were provided in Supplement Data (Table S1). CLs samples were obtained from drugstores and optical shops. The samples were aseptically unpacked on the experiment day and tested for their sterility as the control in all experiments. Briefly, for the sterility test, each lot of CL was enumerated viable microorganisms from aqueous samples. The samples were cultured in a tryptic soy broth (TSB, HiMedia, India) for visual assessment of turbidity to indicate microbial contamination. Moreover, a viable plate count method was performed to determine the growth of bacterial and fungal contamination on tryptic soy agar (TSA, HiMedia, India) and potato dextrose agar (PDA, Sigma-Aldrich, USA), respectively, after incubation at $25^{\circ} \mathrm{C}$ and $37^{\circ} \mathrm{C}$ for $24-48 \mathrm{~h}$.

\section{Bacterial Isolation and Culture}

Bacterial strains including S. aureus ATCC 25923, S. aureus ATCC 29213, S. epidermidis ATCC 35984, 
Table I Soft Contact Lens Characteristics and Properties

\begin{tabular}{|c|c|c|c|c|c|c|c|}
\hline CL Materials & $\begin{array}{c}\text { Oxygen Transmissibility }(-300) \\
\text { Dk/t } \times 10^{-9} \text { barrer } / \mathrm{cm}\end{array}$ & Type & $\begin{array}{l}\text { Water } \\
\text { Content } \\
(\%)\end{array}$ & $\begin{array}{l}\text { FDA } \\
\text { Group }\end{array}$ & $\begin{array}{l}\text { Surface } \\
\text { Treatment }\end{array}$ & $\begin{array}{l}\text { Hydrophilicityl } \\
\text { Hydrophobicity }\end{array}$ & lonicity \\
\hline $\begin{array}{l}\text { HEMA } \\
\text { (Polymacon) }\end{array}$ & 30 & Hydrogel & 42 & 1 & None & Hydrophilic & Non-ionic \\
\hline Ocufilcon D & 19.6 & Hydrogel & 55 & IV & None & Hydrophilic & lonic \\
\hline $\begin{array}{l}\text { Filcon II } 3 \\
\text { (Somofilcon A) }\end{array}$ & 86 & Silicone hydrogel & 56 & v & None & Hydrophilic & Non-ionic \\
\hline Nesofilcon A & 42 & Hydrogel (Hypergel) & 78 & II & None & Hydrophilic & Non-ionic \\
\hline $\begin{array}{l}\text { Printed HEMA } \\
\text { (Polymacon) }\end{array}$ & 8.4 & Hydrogel & 38 & 1 & $\begin{array}{l}\text { Color } \\
\text { printed }\end{array}$ & Hydrophilic & Non-ionic \\
\hline
\end{tabular}

Abbreviation: HEMA, 2-hydroxyethyl methacrylate.

E. coli ATCC 25922, P. aeruginosa ATCC 27853, and K. pneumoniae ATCC 700603 were picked and evaluated their biofilm-producing property. The bacteria were grown on TSA at $37^{\circ} \mathrm{C}$ for $18-24$ h. S. aureus ATCC 29523 and $P$. aeruginosa ATCC 27853 were selected as the representative strains of high biofilm-producing Gram-positive and Gram-negative bacteria, respectively, for the further biofilm removal experiment in this study. All isolates were subcultured and maintained in TSB.

\section{Growth of Bacterial Biofilm}

Bacterial strains were inoculated overnight in TSB, at $37^{\circ}$ C. The inoculation was adjusted to the turbidity of a 0.5 McFarland standard or measured optical density (OD) of 1.0 (approximately $1 \times 10^{8} \mathrm{CFU} / \mathrm{mL}$ ) at $600 \mathrm{~nm}$. The bacterial suspensions were diluted $1: 100$ in $1 \mathrm{~mL}$ of TSB containing $2 \%$ glucose and they were subsequently transferred into sterile flat-bottomed 24-well polystyrene microplates (SPL Life Sciences Co., Korea), with each well containing one contact lens.

\section{Biofilm Biomass on CL Materials}

Biofilm biomass was evaluated by the colorimetric microtiter plate assay as described by O'Toole et al (2011). ${ }^{26}$ Overnight bacterial biofilms were cultured on CLs of different materials, including HEMA, Ocufilcon D, Filcon II 3, Nesofilcon A, and printed HEMA (colored CLs), which were aseptically placed in 24-well plates and incubated at $37^{\circ} \mathrm{C}$ for $24 \mathrm{~h}$. After incubation, the CLs were transferred to new plates. The CLs were gently washed twice with sterile phosphate buffered saline $(\mathrm{pH} 7.3)$ and air-dried. An aliquot of $200 \mu \mathrm{L}$ of $0.1 \%$ crystal violet solution was added to each well to stain the bacterial biofilm for $15 \mathrm{~min}$ at room temperature. Any excess stain was removed by rinsing with distilled water. The biofilm biomass on the CLs was determined by decolorization with $200 \mu \mathrm{L}$ of $33 \%$ acetic acid for $15 \mathrm{~min}$ and quantified by measuring the $\mathrm{OD}$ at $570 \mathrm{~nm}$ using a microtiter plate reader (BioTek Instruments, Inc., USA). All experiments were performed in triplicate and repeated three times.

\section{Preformed Biofilm Removal Efficacy Testing}

S. aureus ATCC 29523 and P. aeruginosa ATCC 27853 were cultured in 24-well plates as described previously. The CLs were immersed in each well of the bacterial suspension and incubated for $24 \mathrm{~h}$ to achieve a matured biofilm on the lens surfaces. Different solutions including saline solution; NSS ( $0.9 \%$ sodium chloride: $\mathrm{NaCl}), \mathrm{ReNu}$ Fresh (multipurpose solution; MPS), and Opti-Free Aldox (multipurpose disinfecting solution; MPDS, containing dual disinfectants Polyquad and Aldox; MPDS+PoA) were employed to clean or disinfect the CLs by soaking according to the recommendations of each manufacturer. The Sensitive Eyes daily cleaner (MPDS containing edetate disodium and sorbic acid; MPDS+EDSA) was applied as a drop-rubbing solution prior to soaking in MPS referred as the two-step system in this study. The direction for user of each CL care solution was provided in Supplement data (Table S2).

Since the manufacturer of some MPS and MPDS provided an alternative no-rub regimen, manual rubbing of 
CLs for 20 seconds before soaking was compared with the soaking without rub in order to evaluate the effectiveness of mechanical biofilm removal. The biomass of bacterial biofilm was measured by a crystal violet staining assay and the number of adherent bacteria was determined by a viable plate count. All experiments were performed in triplicate.

\section{Evaluation of Bacterial Adhesion Activity on CLs}

The bacterial cultures were re-cultured in TSB at $37^{\circ} \mathrm{C}$ for $4 \mathrm{~h}$ and adjusted to achieve a bacterial cell density of $10^{8}$ $\mathrm{CFU} / \mathrm{mL}$. An aliquot of $1 \mathrm{~mL}$ of the bacterial suspension was transferred to a 24-well plate. The CLs were immersed in a bacterial suspension well. Bacterial adhesion on different CL materials was evaluated within a 24 $\mathrm{h}$ period. The amount of adherent bacterial cells was determined at several time intervals $(0,0.5,1,4,8,12$, and $24 \mathrm{~h}$ ).

To determine the anti-adhesion effect of the CL-care solutions, the CLs were placed into a 24-well plate. Each well contained the bacterial suspension of $1.5 \times 10^{6} \mathrm{CFU} /$ well. The volume $2 \mathrm{~mL}$ of the tested disinfecting agents was added into each well. The inhibitory effects of the disinfectants were determined at $6 \mathrm{~h}$ after incubation following the manufacture recommendation. Unattached bacteria on the CLs were removed by NSS-rinsing. The CLs were transferred to the new NSS tubes and sonicated to obtain the adherent bacterial cells. An aliquot of $100 \mu \mathrm{L}$ from the suspension was spread on TSA then incubated overnight at $37^{\circ} \mathrm{C}$. The number of adherent bacteria was enumerated by the standard plate counting method. ${ }^{27,28}$ All experiments were performed in triplicate.

\section{Scanning Electron Microscopy (SEM)}

SEM was performed to evaluate the visualized characteristics of bacterial biofilm formation on the different surfaces of soft CLs. HEMA lenses and printed HEMA lenses were incubated with the cultures of $S$. aureus ATCC 25923 and $P$. aeruginosa ATCC 27853 to grow the biofilm at $37^{\circ} \mathrm{C}$ for $24 \mathrm{~h}$. Surface topography of bacteria grown on CLs were investigated using SEM according to the following protocol. ${ }^{29}$ Briefly, the CL samples were fixed in $2.5 \%$ glutaraldehyde $/ 0.1$ $\mathrm{M}$ cacodylate buffer, $\mathrm{pH} 7.4$ at $4^{\circ} \mathrm{C}$, followed by fixing with $1 \%$ cacodylate osmium tetroxide $\left(\mathrm{OsO}_{4}\right)$, post-fixed at room temperature for $1 \mathrm{~h}$, and subsequently rinsed with sterile water. The lenses underwent alcohol dehydration at a graded series of ethanol concentrations before mounted on aluminum stubs, and sputter-coated with gold in a Cressington 108 Auto Sputter Coater (Cressington Scientific Instruments, UK). The samples were subjected to electron microscopy at the Center for Scientific and Technological Equipment (CSE), Walailak University. Images of each sample were observed at $3 \mathrm{kV}$ under SEM (Merlin Compact, Zeiss, Germany) at the magnifications of $\times 1000, \times 5000$ and $\times 10,000$.

\section{Statistical Analysis}

Statistical differences between groups were determined using GraphPad Prism 6.05 (GraphPad Software, San Diego, CA). All data are expressed as the mean \pm standard error of the mean. To compare the differences among the levels of bacterial biofilm production and adhesion activity on the different CL materials, a one-way analysis of variance (ANOVA) was used for multiple comparisons. A $p$-value of less than 0.05 was considered statistically significant.

\section{Results}

\section{Bacterial Biofilm Formation on Various CL Material Surfaces}

Biofilm producing strains were evaluated for their capability to colonize and form biofilms on five different CL materials (Figure 1). The strains of $S$. aureus and $P$. aeruginosa demonstrated an optical density for the biofilm biomass of $1.67 \pm 0.34$ and $2.27 \pm 0.19$, respectively, representing high biofilm-producing strains of Gram-negative and Gram-positive bacteria compared with the others. In addition, $S$. epidermidis and $K$. pneumoniae showed OD values of $1.56 \pm 0.32$ and $2.18 \pm 0.27$, respectively. E. coli showed the lowest biofilm formation on all tested CL materials with an OD value of $1.40 \pm 0.36$. The results revealed that Filcon II 3 (silicone hydrogel) and Nesofilcon A (hypergel) CLs had the lowest average all-strain biofilm biomasses with OD values of $0.84 \pm 0.27$ and $1.24 \pm 0.37$, respectively. The strongest staining bacterial biofilm was found on the HEMA lenses, especially for $K$. pneumonia with an OD value of $2.52 \pm 0.14$ and $P$. aeruginosa with an OD value of $2.80 \pm 0.03$. Interestingly, the printed HEMA CLs demonstrated a significant influence on bacterial attachment and biofilm formation when compared with nonprinted CLs, Ocufilcon D, Filcon II 3, and Nesofilcon A. The strains of $K$. pneumonia and P. aeruginosa were 


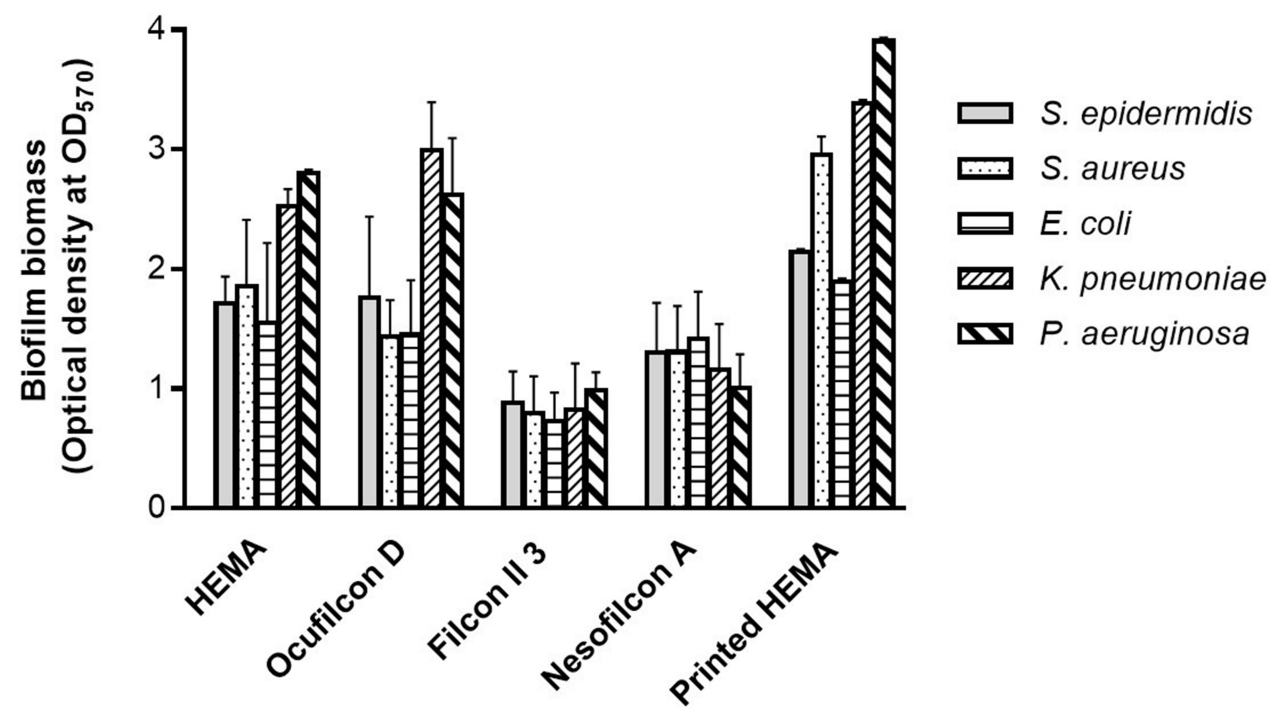

Figure I Evaluation of bacterial biofilm formation of S. epidermidis ATCC 35984, S. aureus ATCC 25923, E. coli ATCC 25922, K. pneumoniae ATCC 700603, and P. aeruginosa ATCC 27853 on various CL material surfaces measured by spectrophotometry at $570 \mathrm{~nm}$. Data are expressed as the mean \pm SEM.

the two bacteria that demonstrated the highest biofilm on printed HEMA lenses with OD values of $3.38 \pm 0.03$ and $3.90 \pm 0.03$, respectively.

\section{Bacterial Adhesion on CL Materials}

Initial adhesion of all tested bacterial strains on the CL surfaces could be obtained the adherent cell numbers approximately $10^{6} \mathrm{CFU} / \mathrm{mL}$ within $30 \mathrm{~min}$. The adhesion of bacteria was increased to $10^{8} \mathrm{CFU} / \mathrm{mL}$ after incubation at $12 \mathrm{~h}$ (Figure 2A-F). All five different CL materials showed no significant difference in the numbers of bacterial adherent cells of each tested strains ( $p$-value $>0.05$ ). However, some detachment of the adherent bacteria on CL surfaces was observed after culture for $12 \mathrm{~h}$. This has resulted in slightly decreased adherent cells of E. coli (Figure 2D), $K$. pneumoniae (Figure 2E), and P. aeruginosa (Figure 2F) on the tested CL materials, whereas the printed HEMA lenses constantly exhibited persistent adherent cell numbers. The bacterial adhesion activity on HEMA lenses compared to printed HEMA lenses did not show a significant difference. This study showed that Nesofilcon A demonstrated a less bacterial adhesion capability in all bacterial strains when compared with those HEMA-based lenses and silicone hydrogel lenses.

\section{Effectiveness of CL-Care Solutions and Cleaning Procedures on the Removal of Preformed Biofilms}

The bacterial biofilms were treated with CL-care solutions including NSS, MPS, MPDS+PoA, and MPDS
+EDSA. The cleaning and disinfecting procedures were performed in the period of $6 \mathrm{~h}$, according to the respective manufacturer's recommendation. The percentage of biofilm removal of $S$. aureus and $P$. aeruginosa on the five CL materials are illustrated in Figure $3 \mathrm{~A}$ and $\mathrm{B}$, respectively. Cleaning with NSS failed to demonstrate the significant effects of biofilm reduction on both bacterial strains when compared with the control (untreated biofilm). MPDS+PoA (no-rub method), MPS (no-rub method), MPS (rub method), and the two-step system (MPDS+EDSA and MPS) expressed the anti-preformed biofilm effects on $S$. aureus biofilms on the different CL materials, ranging from 59.02-94.63\%, 56.64-90.84\%, 49.09-60.18\%, and 87.18-99.17\%, respectively. The biofilm removal activities of the cleaning regimens described above on $P$. aeruginosa demonstrated the percentage of reductions ranging from $13.84-50.62 \%, 11.87-24.03 \%$, $33.72-65.28 \%$, and $58.13-97.79 \%$, respectively. The results of CL care solution effects on bacterial preformed biofilm did not indicate dramatic dissimilarity effectiveness between the cleaning procedures on the five different CL materials.

\section{Anti-Bacterial Adhesion Property of CL-Care Solutions and Procedures}

The biofilm-forming isolates were grown on HEMA and printed HEMA materials while being exposed to the original concentration of three different disinfecting solutions for $6 \mathrm{~h}$. The inhibitory effects of the treatments on $S$. aureus and $P$. aeruginosa are presented in Figure 
A

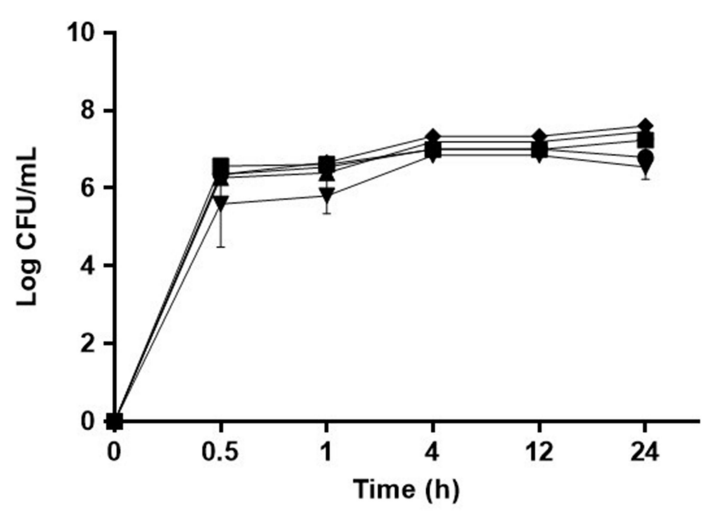

C

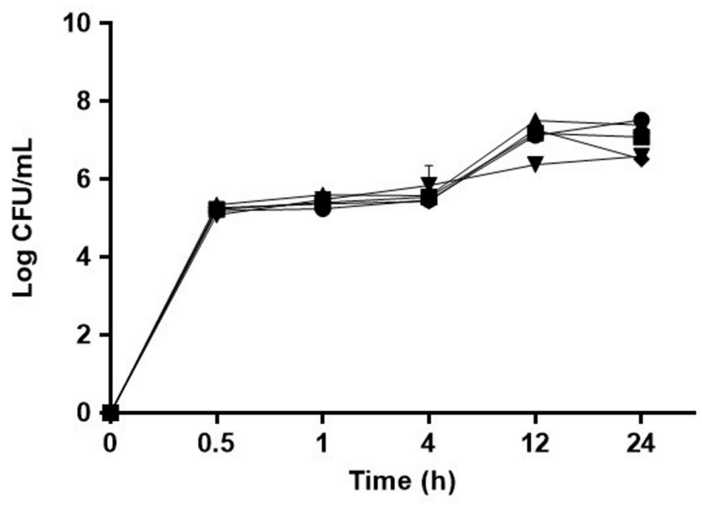

E

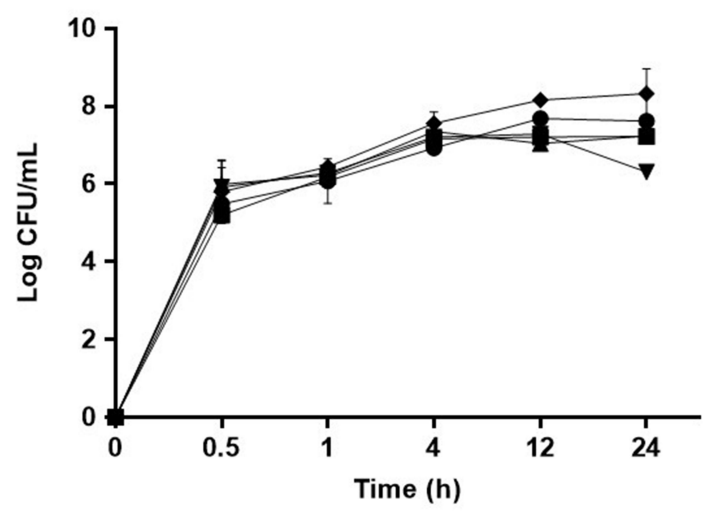

B

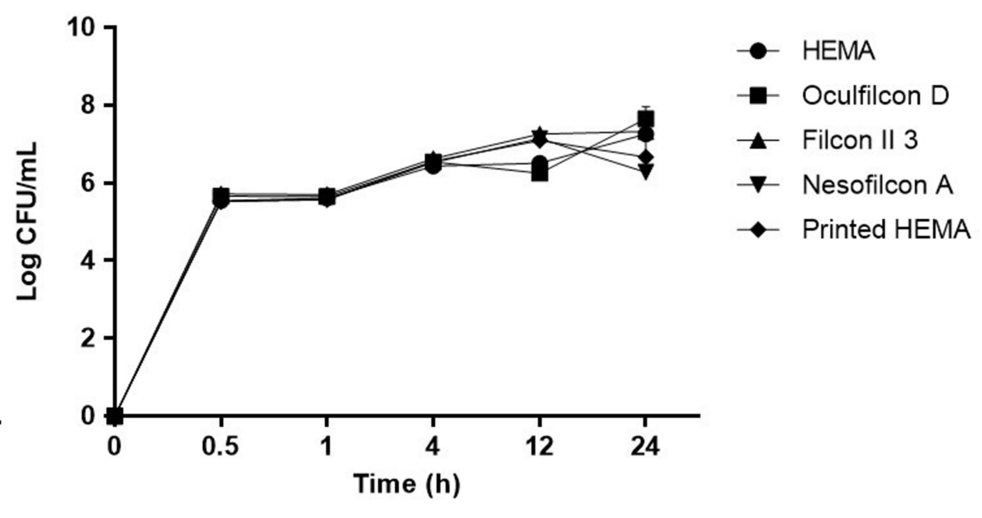

D

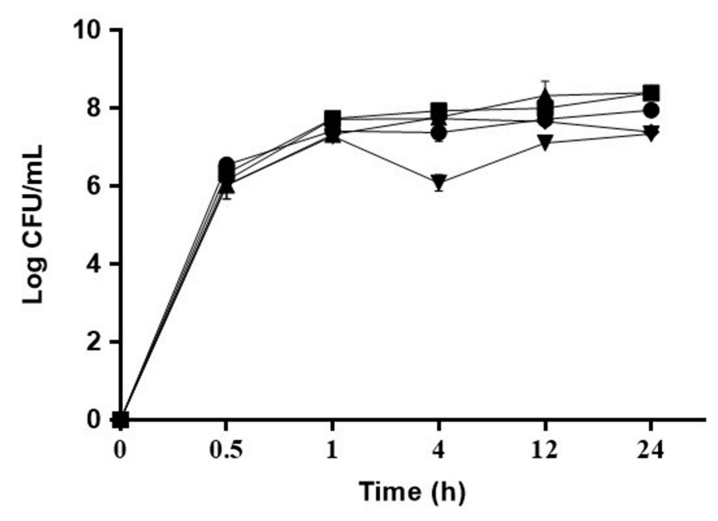

F

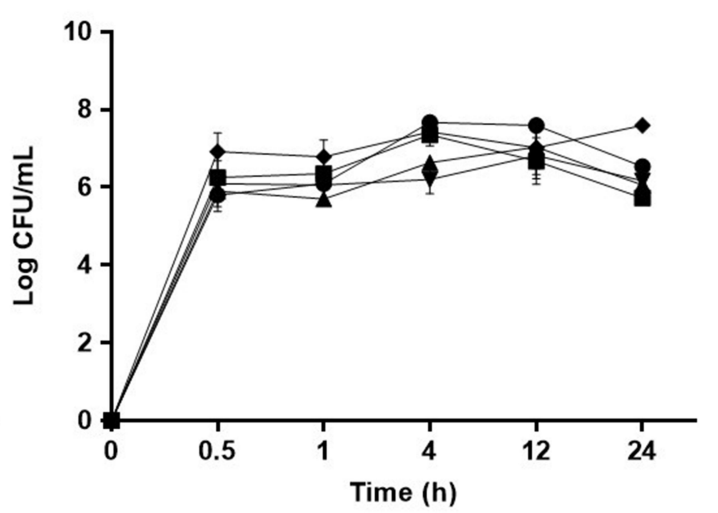

Figure 2 Number of adherent bacteria on CL surfaces: Figures (A-F); S. aureus ATCC 29213 (A), S. aureus ATCC 25923 (B), S. epidermidis ATCC 35984 (C), E. coli ATCC 25922 (D), K. pneumoniae ATCC 700603 (E), and P. aeruginosa ATCC 27853 (F). The evaluation of the time-interval adherent numbers was performed at 0, 0.5, I, 4, I2, and $24 \mathrm{~h}$.

$4 \mathrm{~A}$ and $\mathrm{B}$, respectively. Furthermore, the numbers of adherent cells of $S$. aureus and $P$. aeruginosa cells are illustrated in Figure 4C and D, respectively. All CL-care solutions showed a similar pattern in reducing the adhesion of Gram-positive and Gram-negative bacteria. The solutions exhibited a significant reduction of bacterial adhesion on both the HEMA and printed HEMA lenses when compared with the control $(P<0.05)$. The disinfecting effects of the MPS, MPDS+PoA, and two-step system were possessed a stronger effect on the HEMA surface than on the printed HEMA. In comparing the different CL-care solutions using the no-rub method, the MPDS+PoA provided $66.66-69.78 \%$ of adhesion inhibition effect on the HEMA and $32.23-40.34 \%$ on the 


\section{S. aureus}

A

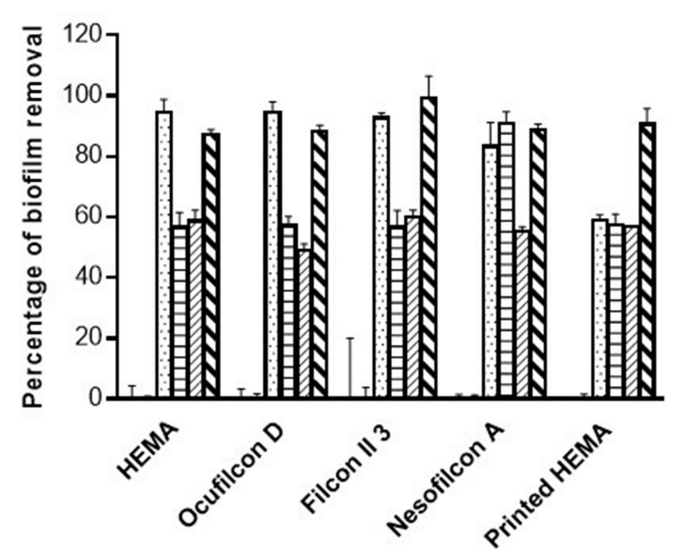

P. aeruginosa

B

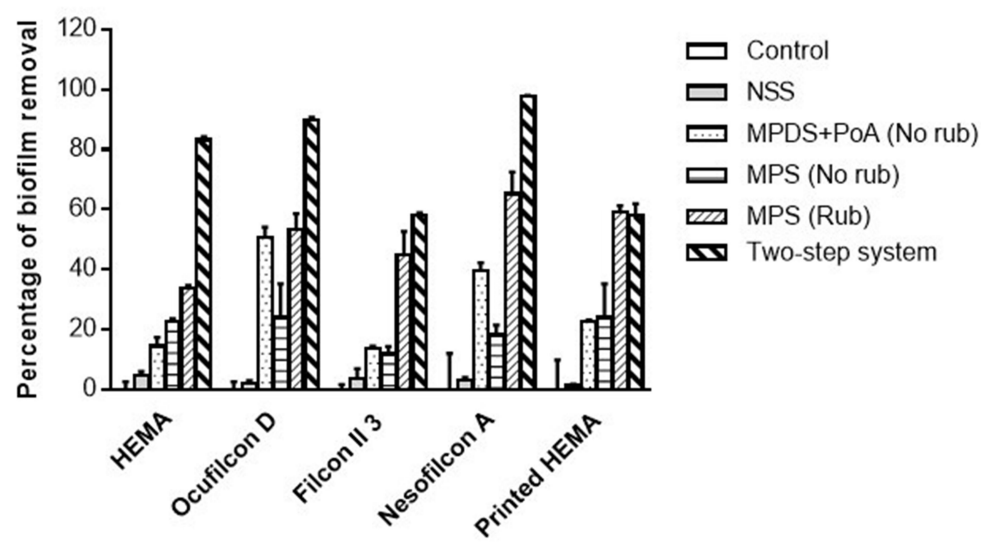

Figure 3 Reduction of biofilm produced by S. aureus ATCC 25923 (A) and P. aeruginosa ATCC 27853 (B) on the different CL materials. The bacterial biofilm was treated with CL-care solutions including NSS, MPS, MPDS+PoA, and two-step system for $6 \mathrm{~h}$ of disinfecting period.

printed HEMA, which were more effective than the MPS. The tested MPS demonstrated the inhibitory effects of $36.62-37.19 \%$ and $19.70-26.09 \%$ on the HEMA and printed HEMA, respectively.

In the rub regimen, CLs rubbing before using the MPS exhibited percentages of inhibition effect ranging from $72.75-79.21 \%$ and $53.75-63.04 \%$ on the HEMA and printed HEMA surfaces, respectively, which higher than the effects of the no-rub method. Interestingly, the twostep system of rubbing CLs with the MPDS+EDSA followed by soaking in the MPS displayed the most effective inhibition against bacterial adhesion with percentages of $77.44-77.84 \%$ and $66.13-69.11 \%$ on the HEMA and printed HEMA surfaces, respectively.

\section{Observation by SEM}

SEM visualization of the CLs after disinfecting for $6 \mathrm{~h}$ in MPS and applying a two-step system is shown in Figure 5. The bacterial adhesion and biofilm phenotypes of $S$. aureus and $P$. aeruginosa are demonstrated in Figure 5A and B, respectively. The untreated CL surfaces showed a greater amount of adherent bacterial cells and more densely attached multilayered biofilm with deeply embedded filaments on the lens surface more than the treated CL samples. The matured biofilms of $P$. aeruginosa demonstrated multilayered rod-shaped bacteria with exopolymeric materials. The cells were encased and interconnected inside a mesh-like structure (Figure 5B upper panel), while the matured biofilm of $S$. aureus showed clustering of the $1 \mu \mathrm{m}$ diameter, spherical-shaped bacteria with lower condensed exopolymeric substances (Figure 5A upper panel).

The biofilms morphological changes associated with the disinfection were observed in both MPS (no rub) treatment and the two-step system. The bacterial cells were organized as small aggregates or as individual cells without any extracellular materials (Figure 5A and B middle and lower panels). Interestingly, $P$. aeruginosa showed signs of cell wall dehydration and cellular damage after $6 \mathrm{~h}$ of treatment with the disinfecting solutions in the middle panels of Figure 5B. The biofilm of $S$. aureus showed the forming of weak biofilm, atypical clusters, and a monolayer given after treatment by the disinfecting agents (Figure 5A middle and lower panels). The SEM images of the HEMA lenses showed more clear surface, and lower biofilm thickening, whereas the rough surface with the condensed biofilm residuals was found in the printed HEMA lenses.

\section{Discussion}

Conventional CLs, especially those made from HEMA, were the most suitable for bacterial adhesion and biofilm formation, which may help to sustain the growth of microorganisms in prolonged contact with the cornea leading to full-blown ocular surface infections or microbial keratitis. $^{30,31}$ The five biofilm-producing bacterial strains associated with eye infections including $S$. aureus, $S$. epidermidis, E. coli, $P$. aeruginosa, and $K$. pneumonia 

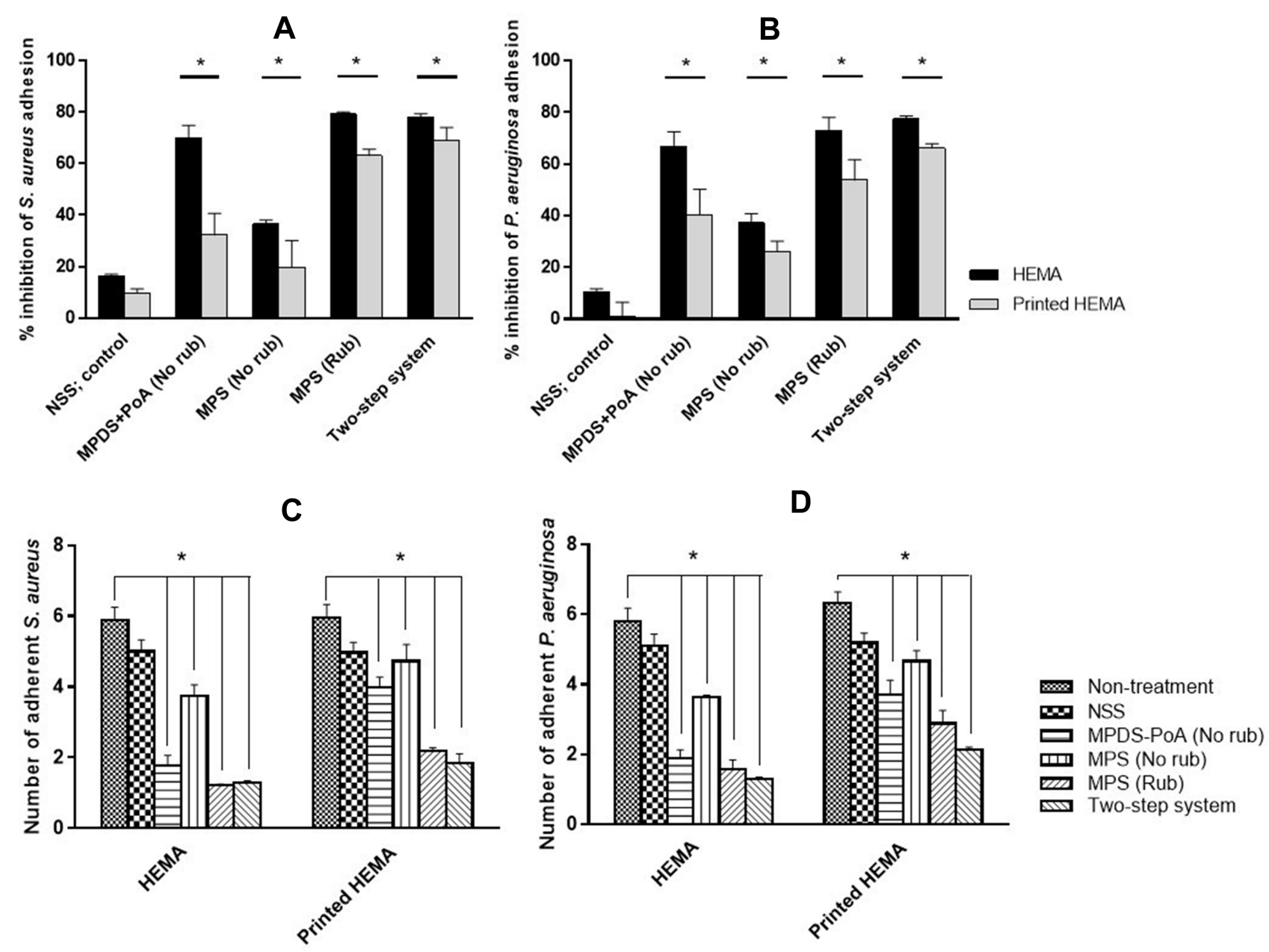

Figure 4 Percentage of inhibitory effects of the CL-care solutions and cleaning regimens on bacterial adhesion of S. aureus ATCC 25923 (A) and P. aeruginosa ATCC 27853 (B). Comparison of bacterial adherent numbers of S. aureus ATCC 25923 (C) and P. aeruginosa ATCC 27853 (D) on CL materials between non-printed HEMA and colorprinted HEMA after exposure to the different disinfecting procedures. $* P$ value $<0.05$ indicated significant differences between the treatments and the control.

were selected for the current study. The bacteria were tested for the adhesion activity and production of biofilm biomass on different groups of CL materials that are commercially available in Thailand market, including HEMA-based, silicone hydrogel, and hypergel. The colorprinted (cosmetic) HEMA lens was included to evaluate the capability of bacterial colonization on irregular surface. Since the surface properties of CLs (eg roughness and hydrophobicity) have been reported to play an important role in the microenvironment of site of bacterial adhesion and biofilm formation, ${ }^{21,22}$ we hypothesized that imperfection of the surface and certain material might facilitate bacterial adhesion and subsequent production of biofilm. However, the effects of the roughness of CL surface on bacterial adhesion is still an issue of controversy; a previous study found the correlation of CLs with rougher surface having less susceptibility to the bacterial adhesion. ${ }^{32}$ The present study demonstrated that bacterial adhesion and biofilm formation were conditional on the different materials of CL. We observed the difference of bacterial adhesion capability between HEMAbased and silicone hydrogel. Nesofilcon A demonstrated a less bacterial adhesion capability in all bacterial strains when compared with those HEMA-based lenses and silicone hydrogel lenses. The printed HEMA lens proved to be the most susceptible material for bacterial adhesion. The findings correlate with the report regarding adhesion of $S$. aureus, P. aeruginosa, and Serratia marcescens on various cosmetic CLs, which indicated that CL surface printing resulted in significantly higher bacterial adhesion. ${ }^{33}$ Moreover, this study showed that the printed HEMA lens presented the highest biofilm biomass formation of all tested bacteria and notably difficult for disinfection. Considering the base material of the printed 
A

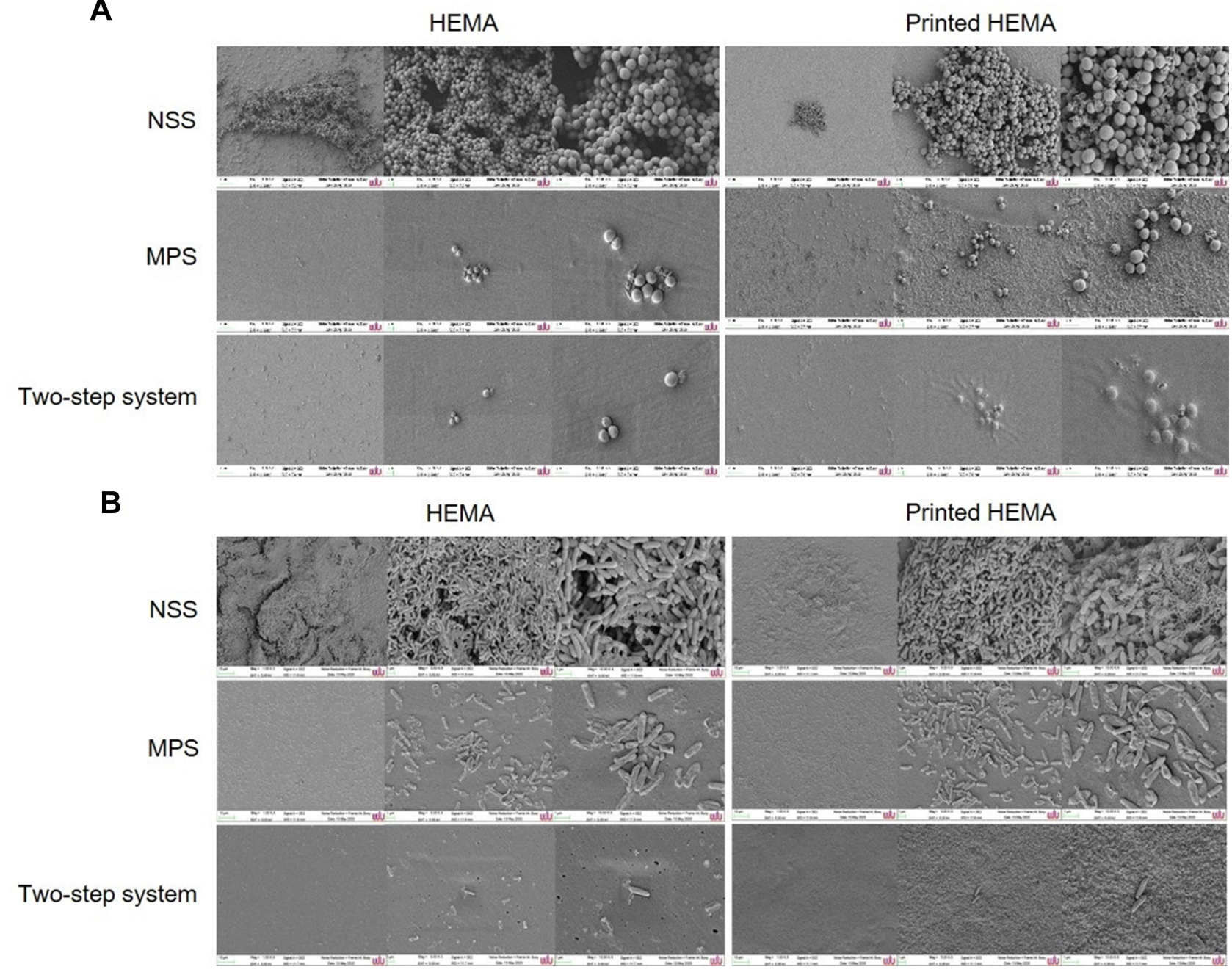

Figure 5 Scanning electron microscopy revealed the biofilm construction produced by S. aureus $(\mathbf{A})$ and $P$. aeruginosa $(\mathbf{B})$ on HEMA and printed HEMA lenses that illustrated in the left panel and right panel, respectively. The biofilm removal efficacy of three different cleaning procedures including soaking in normal saline solution; non-treatment (upper panel), disinfecting with MPS (middle panel), and applying the two-step system (lower panel) are shown in the micrographs.

HEMA lens was the same as the non-printed HEMA lens, the only plausible explanation of the observed phenomenon was the modification of the surface by pigment printing on CL's surface, which resulted in increased surface irregularity ${ }^{34}$ and changes in the chemical property of the surface. ${ }^{35}$ This resulted in a more favorable microenvironment for the organisms. ${ }^{36}$

Furthermore, this study focuses on the effects of the original concentrations of selected disinfecting solutions in order to identify the effectiveness of the real-life procedures that $\mathrm{CL}$ wearers routinely practice. In addition, the minimum inhibitory concentrations (MICs) of each solution were evaluated as described in the "Determination of minimum inhibitory concentration (MIC) and minimum bactericidal concentration $(\mathrm{MBC})$ " section in Supplement data and results are shown the "Results of MICs and MBCs" section in Supplement data and Table S3. The original concentrations of MPS, MPDS+PoA, and MPDS+EDSA solutions were applied and compared for their anti-adhesion and biofilm removal effects during a 6-hour exposure. MPS and MDPS are the major cleaning solutions that are used for soft CL care as a convenient single solution for the multiple purposes of rinsing, disinfecting, providing lens comfort, and cleaning the storage case. The efficacy of MPS versus MPDS has been previously reported, with MPDS possessing the stronger bacterial inhibition and anti-biofilm formation activity. ${ }^{37-39}$ These results were supported by our experiments, where we found that the MPDS+PoA showed stronger adhesion inhibition and the ability to remove preformed biofilm when compared to the MPS. 
To avoid potential bias, the experiments were performed by washing the hands, air drying, wear the hand groove to keep away from dermal contamination, ${ }^{40}$ and gently rub the CLs following manufacturers' recommended guidelines. ${ }^{41}$ Results showed the two-step system of rubbing with the MPDS+EDSA followed by disinfecting with MPS was the most effective regimen to remove preformed biofilm and adherent $S$. aureus or $P$. aeruginosa. The effects against preformed biofilm and bacterial adhesion were reduced when the no-rub technique was applied. Moreover, this study suggested that the biofilm of Gram-negative bacteria possessed more resistance against disinfecting agents and physical rubbing on the tested CL materials. The exposure period of the no-rub method with MPDS or MPS may need to be extended beyond $6 \mathrm{~h}$ to eliminate the preformed biofilm.

The imaging study with SEM also indicated that the cleaning regimen involving friction was key, leading to bacterial detachment and biofilm removal from the CL surface. The authors highly advise that CL users should always rub their CLs regardless of the manufacturer's guidelines for no rub. The formation of biofilm was a major mechanism for bacterial virulence. The biofilm also acted as a defensive impact barrier for bacteria, which was obtained from the secretion of exopolymeric substances. ${ }^{42}$ The hyperproduction was mostly found on hydrophobic substances such as CLs and the storage case. A recent study reported that the formation of bacterial biofilm could be triggered by environmental stress and exposure to disinfecting agents. Activation of defense mechanisms could be indicated by the increased expression of genes related to biofilm formation. ${ }^{43,44}$ The combined rubbing method could be employed to prevent the accumulation of Gram-positive and Gram-negative bacteria from the contamination of storage cases or nonsterile CL solutions. Moreover, the results suggested that the two-step system is the best recommendation for printed HEMA CL care, which is the main material for cosmetic CLs and monthly CLs.

\section{Conclusion}

The presence of bacterial biofilm on the CL surface has a key role in the development of microbial keratitis since the biofilm-producing strains can survive after being disinfected with existing solutions on the market. Moreover, the different properties of each lens material could affect bacterial adhesion differently. This study evidenced that the HEMA-based soft CLs could facilitate the bacteria to enhance their biofilm formation and adhesion activity, especially on printed HEMA or cosmetic colored CLs. For the biofilm removal, this study suggested that the twostep system was the most effective regimen, where the soaking with MDPS+EDSA showed more effective remove pre-formed biofilm than MPS solution of the norub regimen.

\section{Abbreviations}

${ }^{\circ} \mathrm{C}$, degree celsius; ATCC, American Type Culture Collection; $\mathrm{CFU}$, colony forming units; $\mathrm{CL}$, contact lens; D, dioptres; E. coli, Escherichia coli; h, hour; HEMA, 2-hydroxyethyl methacrylate; $K$. pneumonia, Klebsiella pneumonia; M, molar; MA, methacrylic acid; $\mathrm{mL}$, milliliter; MPDS, multipurpose disinfecting solution; MPDS+EDSA, multipurpose disinfecting solution containing edetate disodium and sorbic acid; MPDS + PoA, multipurpose disinfecting solution containing dual disinfectants Polyquad and Aldox; MPS, multipurpose solution; nm, nanometer; NSS, normal saline solution; NVP, N-vinyl pyrrolidone; OD, optical density; P. aeruginosa, Pseudomonas aeruginosa; S. aureus, Staphylococcus aureus; S. epidermidis, Staphylococcus epidermidis; SEE, scanning electron microscopy; TEGDMA, tetraethylene glycol dimethacrylate; TSA, tryptic soy agar; $\mathrm{TSB}$, tryptic soy broth; $\mu \mathrm{L}$, microliter; $\mu \mathrm{m}$, micrometer.

\section{Acknowledgments}

The authors are grateful to the Excellence Research Laboratory on Natural Products, Faculty of Science and Natural Product Research Center of Excellence, Prince of Songkla University, Thailand, for providing the bacterial strains. We would also like to thank the Research Center of Excellence in Innovation on Essential oil and Research Institute for Health Science, Walailak University for kind supports and laboratory facilities.

\section{Funding}

This work was supported by Walailak University, Thailand, Grant Number WU-IRG-63-032, 2020.

\section{Disclosure}

The authors report no conflicts of interest in this work. 


\section{References}

1. Resnikoff S, Pascolini D, Mariotti SP, Pokharel GP. Global magnitude of visual impairment caused by uncorrected refractive errors in 2004. Bull World Health Organ. 2008;86(1):63-70. doi:10.2471/ blt.07.041210

2. Cope JR, Collier SA, Rao MM, et al. Contact lens wearer demographics and risk behaviors for contact lens-related eye infections United States, 2014. MMWR Morb Mortal Wkly Rep. 2015;64 (32):865-870. doi:10.15585/mmwr.mm6432a2

3. Ibrahim NK, Seraj H, Khan R, Baabdullah M, Reda L. Prevalence, habits and outcomes of using contact lenses among medical students. Pak J Med Sci. 2018;34(6):1429-1434. doi:10.12669/pjms.346.16260

4. Panthi S, Paudel P, Chaudhary M, Sapkota K, Shah DN. Microbial contamination of contact lens care accessories and compliance with care regimens in Nepal. Cont Lens Anterior Eye. 2014;37(1):2-10. doi:10.1016/j.clae.2013.07.001

5. Bowden T, Nosch DS, Harknett T. Contact lens profile: a tale of two countries. Cont Lens Anterior Eye. 2009;32(6):273-282. doi:10.1016/ j.clae.2009.09.002

6. Wu Y, Carnt N, Stapleton F. Contact lens user profile, attitudes and level of compliance to lens care. Cont Lens Anterior Eye. 2010;33 (4):183-188. doi:10.1016/j.clae.2010.02.002

7. Dumbleton KA, Woods CA, Jones LW, Fonn D. The relationship between compliance with lens replacement and contact lens-related problems in silicone hydrogel wearers. Cont Lens Anterior Eye. 2011;34(5):216-222. doi:10.1016/j.clae.2011.03.001

8. Wu YT, Tran J, Truong M, Harmis N, Zhu H, Stapleton F. Do swimming goggles limit microbial contamination of contact lenses? Optom Vis Sci. 2011;88(4):456-460. doi:10.1097/ OPX.0b013e31820f15a6

9. de Oliveira PR, Temporini-Nastari ER, Ruiz Alves M, Kara-José N. Self-evaluation of contact lens wearing and care by college students and health care workers. Eye Contact Lens. 2003;29(3):164-167. doi:10.1097/01.Ic1.0000072829.76899.B5

10. Donshik PC, Ehlers WH, Anderson LD, Suchecki JK. Strategies to better engage, educate, and empower patient compliance and safe lens wear: compliance: what we know, what we do not know, and what we need to know. Eye Contact Lens. 2007;33(6):430-433. doi:10.1097/ICL.0b013e318157f62a

11. Polse KA, Brand RJ, Cohen SR, Guillon M. Hypoxic effects on corneal morphology and function. Invest Ophthalmol Vis Sci. 1990;31(8):1542-1554.

12. Miller MJ, Ahearn DG. Adherence of Pseudomonas aeruginosa to hydrophilic contact lenses and other substrata. J Clin Microbiol. 1987;25(8):1392-1397. doi:10.1128/jcm.25.8.1392-1397.1987

13. Cook AD, Sagers RD, Pitt WG. Bacterial adhesion to protein-coated hydrogels. $J$ Biomater Appl. 1993;8(1):72-89. doi:10.1177/ 088532829300800105

14. Alexandrakis G, Alfonso EC, Miller D. Shifting trends in bacterial keratitis in south Florida and emerging resistance to fluoroquinolones. Ophthalmology. 2000;107(8):1497-1502. doi:10.1016/s0161-6420(00)00179-2

15. Lam DS, Houang E, Fan DS, Lyon D, Seal D, Wong E. Incidence and risk factors for microbial keratitis in Hong Kong: comparison with Europe and North America. Eye (Lond). 2002;16(5):608-618. doi:10.1038/sj.eye. 6700151

16. Bharathi MJ, Ramakrishnan R, Shivakumar C, Meenakshi R, Lionalraj D. Etiology and antibacterial susceptibility pattern of community-acquired bacterial ocular infections in a tertiary eye care hospital in south India. Indian $J$ Ophthalmol. 2010;58 (6):497-507. doi:10.4103/0301-4738.71678

17. Costerton JW, Montanaro L, Arciola CR. Biofilm in implant infections: its production and regulation. Int J Artif Organs. 2005;28 (11):1062-1068. doi:10.1177/039139880502801103
18. Donlan RM, Costerton JW. Biofilms: survival mechanisms of clinically relevant microorganisms. Clin Microbiol Rev. 2002;15 (2):167-193. doi:10.1128/cmr.15.2.167-193.2002

19. McLaughlin-Borlace L, Stapleton F, Matheson M, Dart JK. Bacterial biofilm on contact lenses and lens storage cases in wearers with microbial keratitis. J Appl Microbiol. 1998;84(5):827-838. doi:10.1046/j.1365-2672.1998.00418.x

20. Selan L, Palma S, Scoarughi GL, et al. Phosphorylcholine impairs susceptibility to biofilm formation of hydrogel contact lenses. $\mathrm{Am}$ J Ophthalmol. 2009;147(1):134-139. doi:10.1016/j.ajo.2008.07.032

21. Bos R, van der Mei HC, Busscher HJ. Physico-chemistry of initial microbial adhesive interactions-its mechanisms and methods for study. FEMS Microbiol Rev. 1999;23(2):179-230. doi:10.1111/ j.1574-6976.1999.tb00396.x

22. Bruinsma GM, Rustema-Abbing M, de Vries J, et al. Multiple surface properties of worn RGP lenses and adhesion of Pseudomonas aeruginosa. Biomaterials. 2003;24(9):1663-1670. doi:10.1016/ s0142-9612(02)00542-2

23. Alves M, Castanheira EMS, Lira M. Interactions between contact lenses and lens care solutions: influence in optical properties. Cont Lens Anterior Eye. 2021;101414. doi:10.1016/j.clae.2021.01.009

24. Lira M, Silva R. Effect of lens care systems on silicone hydrogel contact lens hydrophobicity. Eye Contact Lens. 2017;43(2):89-94. doi:10.1097/icl.0000000000000247

25. Lira M, Franco S, Vazquez-Dorrio JB, Real Oliveira ME, Costa MF. Surface roughness and refractive index changes in contact lens induced by lens care systems. Eye Contact Lens. 2014;40 (3):140-147. doi:10.1097/icl.0000000000000023

26. O'Toole GA. Microtiter dish biofilm formation assay. $J$ Vis Exp. 2011;(47). doi:10.3791/2437

27. Mordmuang A, Shankar S, Chethanond U, Voravuthikunchai S. Effects of Rhodomyrtus tomentosa leaf extract on Staphylococcal adhesion and invasion in bovine udder epidermal tissue model. Nutrients. 2015;7(10):8503-8517. doi:10.3390/nu7105410

28. Maturin L, Peeler J. BAM: Aerobic Plate Count. USA: Bacteriological analytical manual Food and Drug Administration; 2001.

29. Wiley L, Bridge DR, Wiley LA, Odom JV, Elliott T, Olson JC. Bacterial biofilm diversity in contact lens-related disease: emerging role of Achromobacter, Stenotrophomonas, and Delftia. Invest Ophthalmol Vis Sci. 2012;53(7):3896-3905. doi:10.1167/iovs.11-8762

30. Elder MJ, Stapleton F, Evans E, Dart JK. Biofilm-related infections in ophthalmology. Eye (Lond). 1995;9(1):102-109. doi:10.1038/ eye.1995.16

31. Alipour F, Khaheshi S, Soleimanzadeh M, Heidarzadeh S, Heydarzadeh S. Contact lens-related complications: a review. J Ophthalmic Vis Res. 2017;12(2):193-204. doi:10.4103/jovr. jovr_159_16

32. Giraldez MJ, Resua CG, Lira M, et al. Contact lens hydrophobicity and roughness effects on bacterial adhesion. Optom Vis Sci. 2010;87 (6):426-431. doi:10.1097/OPX.0b013e3181da8656

33. Chan KY, Cho P, Boost M. Microbial adherence to cosmetic contact lenses. Cont Lens Anterior Eye. 2014;37(4):267-272. doi:10.1016/j. clae.2013.12.002

34. Hotta F, Eguchi H, Imai S, Miyamoto $\mathrm{T}$, Mitamura-Aizawa S, Mitamura Y. Scanning electron microscopy findings with energy-dispersive X-ray investigations of cosmetically tinted contact lenses. Eye Contact Lens. 2015;41(5):291-296. doi:10.1097/ icl.0000000000000122

35. Dutta D, Cole N, Willcox M. Factors influencing bacterial adhesion to contact lenses. Mol Vis. 2012;18:14-21.

36. Vermeltfoort PB, Rustema-Abbing M, de Vries J, et al. Influence of day and night wear on surface properties of silicone hydrogel contact lenses and bacterial adhesion. Cornea. 2006;25(5):516-523. doi:10.1097/01.ico.0000230324.28956.77 
37. Szczotka-Flynn LB, Imamura Y, Chandra J, et al. Increased resistance of contact lens-related bacterial biofilms to antimicrobial activity of soft contact lens care solutions. Cornea. 2009;28(8):918-926. doi:10.1097/ICO.0b013e3181a81835

38. Kilvington S. Bacteria biofilms provide protection from disinfection by multipurpose contact lens care solutions. Cont Lens Anterior Eye. 2015;38:11-12. doi:10.1016/j.clae.2014.11.115

39. El-Ganiny AM, Shaker GH, Aboelazm AA, El-Dash HA. Prevention of bacterial biofilm formation on soft contact lenses using natural compounds. J Ophthalmic Inflamm Infect. 2017;7(1):11. doi:10.1186/ s12348-017-0129-0

40. Sweeney D, Holden B, Evans K, Ng V, Cho P. Best practice contact lens care: a review of the Asia Pacific contact lens care summit. Clin Exp Optom. 2009;92(2):78-89. doi:10.1111/j.1444-0938.2009.00353. $\mathrm{x}$

41. Campbell D, Mann A, Hunt O, Santos LJ. The significance of hand wash compliance on the transfer of dermal lipids in contact lens wear. Cont Lens Anterior Eye. 2012;35(2):71-76. quiz 96-77. doi:10.1016/ j.clae.2011.11.004
42. Szczotka-Flynn LB, Pearlman E, Ghannoum M. Microbial contamination of contact lenses, lens care solutions, and their accessories: a literature review. Eye Contact Lens. 2010;36(2):116-129. doi:10.1097/ICL.0b013e3181d20cae

43. Roy R, Tiwari M, Donelli G, Tiwari V. Strategies for combating bacterial biofilms: a focus on anti-biofilm agents and their mechanisms of action. Virulence. 2018;9(1):522-554. doi:10.1080/ 21505594.2017.1313372

44. Singh S, Singh SK, Chowdhury I, Singh R. Understanding the mechanism of bacterial biofilms resistance to antimicrobial agents. Open Microbiol J. 2017;11(1):53-62. doi:10.2174/187428580 1711010053
Clinical Ophthalmology

\section{Publish your work in this journal}

Clinical Ophthalmology is an international, peer-reviewed journal covering all subspecialties within ophthalmology. Key topics include: Optometry; Visual science; Pharmacology and drug therapy in eye diseases; Basic Sciences; Primary and Secondary eye care; Patient Safety and Quality of Care Improvements. This journal is indexed on PubMed

\section{Dovepress}

Central and CAS, and is the official journal of The Society of Clinical Ophthalmology (SCO). The manuscript management system is completely online and includes a very quick and fair peer-review system, which is all easy to use. Visit http://www.dovepress.com/ testimonials.php to read real quotes from published authors. 